\title{
IATROGENIC FRACTURES OF THE FEMORAL NECK DURING CLOSED NAILING OF THE FEMORAL SHAFT
}

\author{
PETER T. SIMONIAN, JENS R. CHAPMAN, HUGH S. SELZNICK, STEPHEN K. BENIRSCHKE, \\ BERND F. CLAUDI, MARC F. SWIONTKOWSKI \\ From the University of Washington, Seattle, USA
}

We have reviewed our experience of four iatrogenic femoral neck fractures in 315 consecutive closed intramedullary nailings with the AO/ASIF universal femoral nail. The average neck-shaft angle in the bones that fractured was $139.3^{\circ} \pm 1.2^{\circ} \mathrm{SD}(136$ to 141$)$; in the whole series the average neck-shaft angle was $125.3^{\circ} \pm 8.6^{\circ}$ and only 11 had angles of more than $135^{\circ}$. The upper ends of the nails in the four which fractured were $17 \mathrm{~mm}, 5 \mathrm{~mm}, 3 \mathrm{~mm}$, and $1 \mathrm{~mm}$ below the tip of the greater trochanter.

In the seven patients with neck-shaft angles greater than $135^{\circ}$ but with no fracture, none of the nails had been inserted beyond the tip of the greater trochanter.

We nailed six cadaver femora to simulate the forces produced by intramedullary nailing. Despite deep insertion, only one of the six sustained a neck fracture. This specimen had a radiographic neck-shaft angle of $140^{\circ}$ against an average of $127.3^{\circ} \pm 4.0^{\circ}$ for the other five.

We believe that the medial prong of the $\mathrm{AO}$ insertion jig, with its medial overhang of 2 to $3 \mathrm{~mm}$, may impinge on the superior aspect of a valgus femoral neck during final impaction, causing a neck fracture. This may be avoided by leaving the end of the nail above the tip of the trochanter in such cases.

J Bone Joint Surg [Br] 1994; 76-B:293-6.

Received 30 April 1993; Accepted after revision 5 August 1993

P. T. Simonian, MD, Resident

J. R. Chapman, MD, Assistant Professor

H. S. Selznick, MD, Fellow

S. K. Benirschke, MD, Associate Professor

M. F. Swiontkowski, MD, Professor

Department of Orthopaedics, Harborview Medical Center, University of

Washington, 325 Ninth Avenue, ZA-48, Seattle, Washington 98104-2499,

USA.

B. F. Claudi, MD, Professor

Chirurgische Klinik, Klinikum rechts der Isar, Ismaningerstrasse 22, 8000 Munich 80, Germany.

Correspondence should be sent to Dr P. T. Simonian at the University of Washington Medical Center, Department of Orthopaedic Surgery, RK-10, Seattle, Washington 98105-9950, USA.

(C)1994 British Editorial Society of Bone and Joint Surgery

0301-620X/94/2729\$2.00
Closed intramedullary nailing of the femur for shaft fracture has considerable advantages, but the selection of the starting point is important. Küntscher (1967) recommended insertion of his nail through the tip of the greater trochanter to avoid possible damage to the hip. Winquist, Hansen and Clawson (1984) found that this was associated with increased proximal and medial comminution in some cases, and recommended introduction through the piriformis fossa. Many other authors have also advocated nail entry medially and posteriorly at the base of the greater trochanter (McMaster, Prietto and Rovner 1980; King and Rush 1981; Winquist et al 1984; Harper 1985).

In 1986, Harper and Henstorf reported two cases of iatrogenic fracture of the femoral neck during closed intramedullary nailing of the femur. The radiographs in their paper appeared to show the use of Sampson nails, and they considered that the fractures were due to misdirection of the nails with damage to the medial aspect of the femoral neck. Christie and Court-Brown (1988) found four femoral neck fractures in 143 consecutive closed nailings, and thought that insertion had been oblique in all four, with too lateral a starting point. The neck fractures were vertical, becoming extracapsular inferiorly, and only slightly displaced; the radiographs appear to show Grosse-Kempf nails.

There have been many studies of ipsilateral hip and femoral shaft fracture (Dencker 1965; Casey and Chapman 1979; Zettas and Zettas 1981; Swiontkowski, Hansen and Kellam 1984; Friedman and Wyman 1986; Swiontkowski 1987) and failure to recognise the neck fracture until later has been reported in up to $30 \%$ of cases. Avascular necrosis is uncommon in combined ipsilateral fractures because of the more lateral position of the fracture line (Böhler and Aichner 1959).

Radiographs with the hip internally rotated are necessary to give the best visualisation of the medial femoral neck; most emergency anteroposterior (AP) radiographs of the pelvis fail to show a concomitant neck fracture, because they are taken in external rotation.

In the four cases that we report, there was no evidence of femoral neck fracture in the preoperative or immediate postoperative radiographs. All four were diagnosed at routine follow-up about two weeks later and we postulate that they were iatrogenic and related to a valgus neckshaft angle which allowed the insertion jig to impinge on 


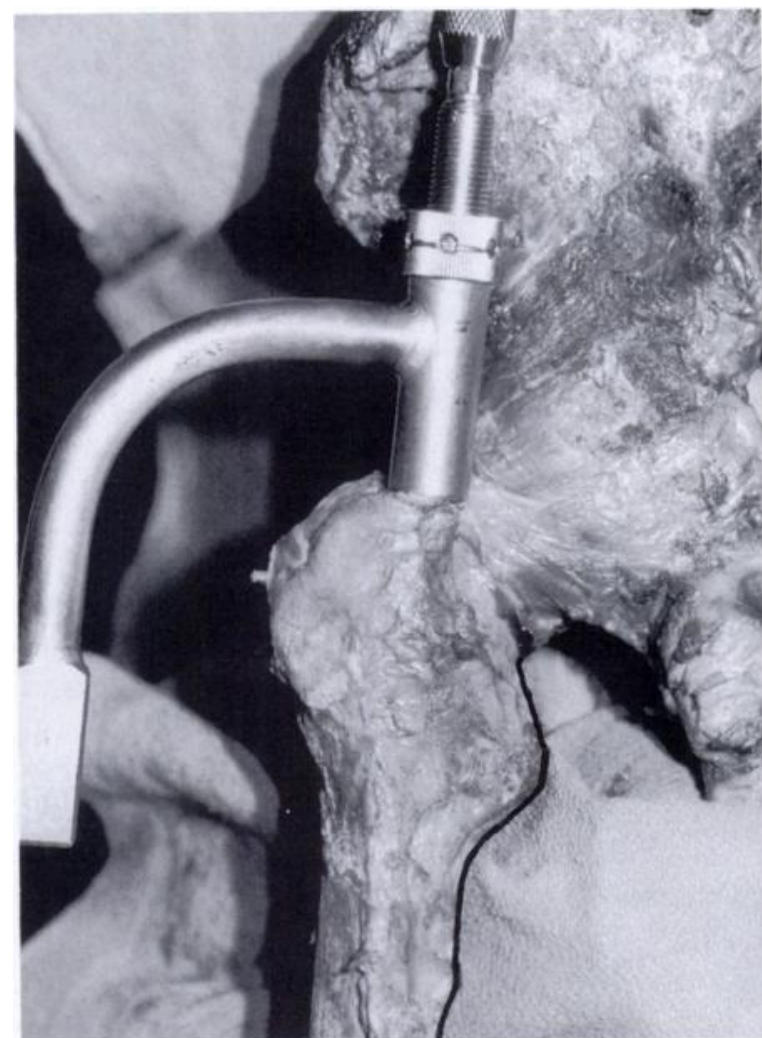

Fig. 1

Cadaver specimen to show the position of the insertion jig.

the superior femoral neck during impaction of the femoral nail.

\section{PATIENTS AND METHODS}

We reviewed our experience of closed femoral nailing and made radiographic measurements of neck-shaft angles in a blind manner as to the occurrence of neck fracture. We also performed experiments on six cadaver femora.

Clinical study. In a four-year period, 315 closed intramedullary nailings were performed for femoral shaft fractures, using the AO/ASIF universal femoral nail. There were 96 females and 219 males; their average age was 29 years (13 to 75$)$. The average radiographic neckshaft angle in the whole series was $125.3^{\circ} \pm 8.6^{\circ} \mathrm{SD}$. Only 11 patients had neck-shaft angles greater than $136^{\circ}$, and all four iatrogenic neck fractures were in this group. There were three females and one male; their average age was 34 years. Two of the patients had been nailed in the supine position and two in the lateral position; one $11 \mathrm{~mm}$, two $12 \mathrm{~mm}$ and one $13 \mathrm{~mm}$ nail had been used. Preoperative and immediate postoperative radiographs showed no neck fractures, but they became apparent on radiographs taken at $11,12,14$ and 17 days respectively. The average radiographic neck-shaft angle measured in these four was $139.3^{\circ} \pm 1.2^{\circ}$ (136 to 141 ).

The seven patients with neck-shaft angles of more than $135^{\circ}$ but no neck fracture had an angle of $138.1^{\circ} \pm$ $1.7^{\circ}$ (136 to 143 ); their average age was 29 years. Five patients were nailed in the lateral position and two in the supine position. Three were female and four were male.

Cadaver study. We studied six fresh-frozen femora, still attached to the pelvis by the hip capsule, from cadavers of average age 76 years. The femur in each specimen was cut at mid-shaft level, and the pelvis was mounted in a holding clamp. An AO nail was inserted (Fig. 1). The starting point, directly seen, was the piriformis fossa. A T-handled reamer was used to penetrate the proximal metaphyseal bone and a guide wire was placed in the femoral canal. Progressive reaming was done with care to avoid eccentric placement. An AO nail was then placed in the $\mathrm{AO}$ jig in the proper orientation and impacted with the slap hammer. Impaction continued using maximum force until advancement was no longer possible because the nail-end was flush with the femoral neck.

\section{RESULTS}

Clinical study. The four iatrogenic fractures were all of Pauwel's type III with varying degrees of displacement. Nail insertion had been to $17 \mathrm{~mm}, 5 \mathrm{~mm}, 3 \mathrm{~mm}$, and $1 \mathrm{~mm}$ below the tip of the great trochanter. The starting points for nailing were in the piriformis fossa in both views in three cases and 2 to $3 \mathrm{~mm}$ posterior in one.

In the seven other patients with neck-shaft angles of greater than $136^{\circ}$ and no neck fractures, the nails were never beyond the tip of the greater trochanter.

Three of the fractures were treated by percutaneous cannulated screw fixation; one required open reduction and internal fixation. After an average follow-up of 6.7 months there have been no complications, such as AVN or nonunion.

Cadaver study. Of the six cadaver femurs nailed in the laboratory, only one sustained a femoral neck fracture on inspection and radiography. This had the same vertical orientation as those in the clinical study (Fig. 2). The

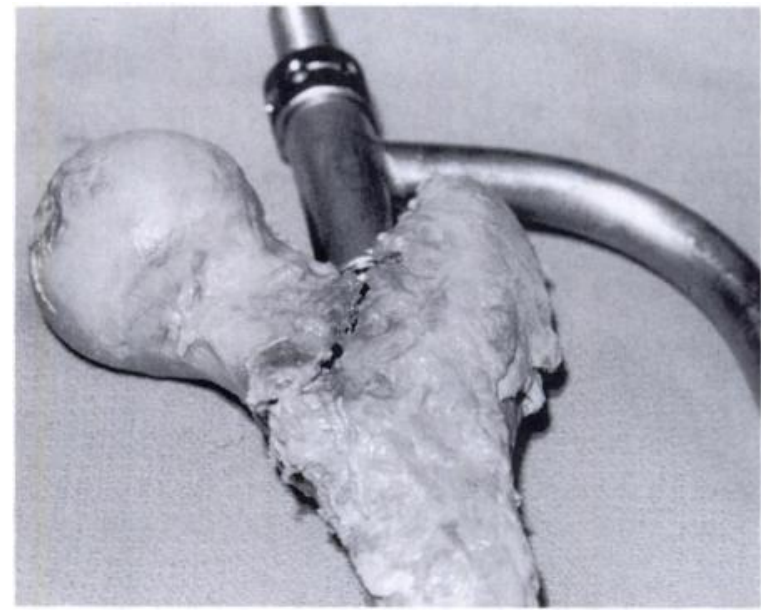

Fig. 2

Femoral neck fracture produced in a cadaver specimen with an excessively valgus femoral neck by impaction of an intramedullary AO nail 


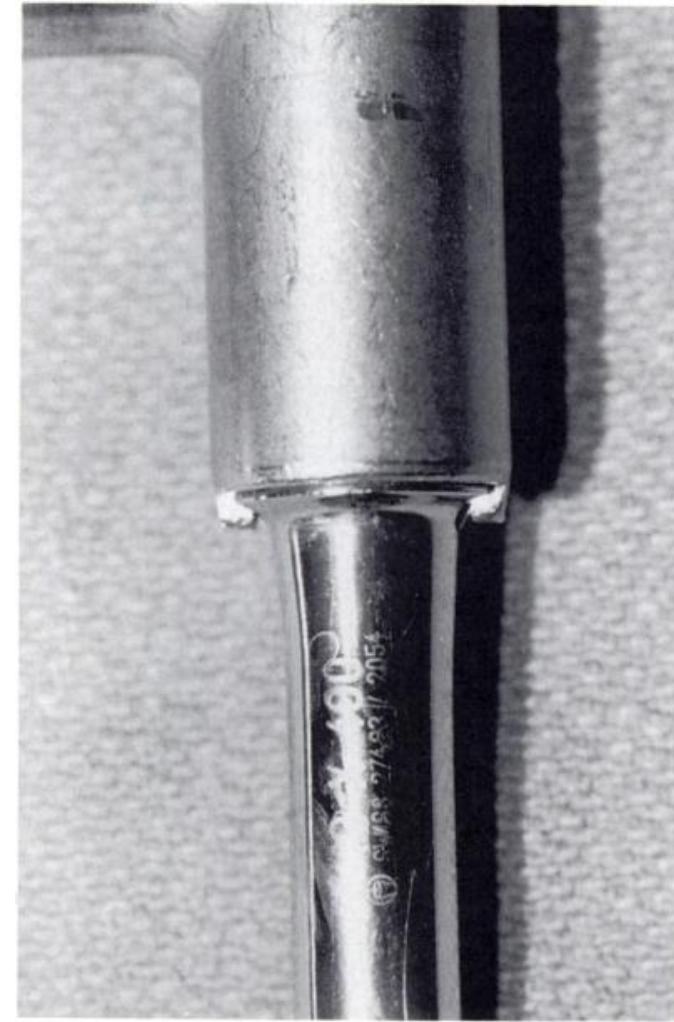

Fig. 3

The AO universal insertion jig, showing the 2 to $3 \mathrm{~mm}$ overhang medial and lateral to the upper end of the nail.

average radiographic neck-shaft angle was $130^{\circ}$ in the unfractured group and $140^{\circ}$ in the fractured specimen.

\section{DISCUSSION}

Closed intramedullary nailing has become the treatment of choice for virtually all femoral shaft fractures (Rothwell 1982; Winquist et al 1984; Hooper and Lyon 1988).

Küntscher originally advised starting the nail at the tip of the greater trochanter to avoid damage to the blood supply of the femoral head and to avoid opening the capsule of the hip which might lead to infection (Küntscher 1967). The piriformis fossa, however, is now the preferred site. Biomechanical studies have shown that an anterior placement increases hoop stresses (Thompson et al 1985; Johnson, Tencer and Sherman 1987) and this was recently confirmed by Miller et al (1993) in a cadaver study which also showed that an anterior entry is more likely to result in femoral neck fracture. An oblique position of the nail with a starting point too lateral in the trochanteric region has also been associated with intraoperative neck fractures (Christie and Court-Brown 1988).

In our total series, the average neck-shaft angle was $125.3^{\circ} \pm 8.6^{\circ}$, agreeing with previously reported values (Noble et al 1988). Only 11 patients had neck-shaft angles of over $136^{\circ}$ and four of these sustained neck fractures.

In both the clinical and cadaver series the starting hole was in the piriformis fossa, but in the clinical series two nails were impacted too deeply, to 12 and $17 \mathrm{~mm}$ below the tip of the greater trochanter. In the cadaver series we impacted each nail as deeply as possible, flush with the femoral neck, but only one of the six specimens fractured. It therefore seems likely that femoral neck fractures are not entirely due either to an improper starting point or excess depth of insertion.

A femoral neck fracture discovered after shaft nailing may be caused by injury at the time of the accident ( Wu and Shih 1991; Johnson 1992). These fractures may be undisplaced, and it is essential that the femoral neck is imaged adequately before shaft nailing. In our series all the femoral necks were well seen on films taken in internal rotation and centred on the femoral neck but we did not confirm the absence of fractures by isotope or CT scans.

The four clinical and one cadaver femoral neck that fractured all had a relatively valgus neck-shaft angle and an increased depth of insertion of the AO nail. It seems that the insertion jig with its medial prong overhang of 2 to $3 \mathrm{~mm}$ (Fig. 3) may impinge on the upper aspect of a valgus femoral neck during final impaction, providing an unrecognised contact point. Given the potential consequences of an untreated or unrecognised femoral neck fracture (Swiontkowski et al 1984; Swiontkowski 1987), we recommend that special care should be taken when the femoral neck is in a valgus position. The depth of insertion of the intramedullary nail should be carefully imaged during final impaction and this should stop before the jig assembly can make contact with the femoral neck. In such cases, this may occur before the upper end of the nail is flush with the tip of the greater trochanter, and it is preferable that the nail should remain proud.

No benefits in any form have been received or will be received from a commercial party related directly or indirectly to the subject of this article.

\section{REFERENCES}

Böhler J, Aichner H. Gleichzeitiger bruch des Oberschenkelschaftes und des Schenkelhalses. Chirurg 1959; 30:557-9.

Casey MJ, Chapman MW. Ipsilateral concomitant fractures of the hip and femoral shaft. J Bone Joint Surg [Am] 1979; 61-A:503-9.

Christie J, Court-Brown C. Femoral neck fracture during closed medullary nailing: brief report. J Bone Joint Surg [Br] 1988; 70-B:670.

Dencker H. Femoral shaft fracture and fracture of the neck of the same femur. Acta Chir Scand 1965; 129:597-605.

Friedman RJ, Wyman ET. Ipsilateral hip and femoral shaft fractures. Clin Orthop 1986; 208:188-94.

Harper MC. Fractures of the femur treated by open and closed intramedullary nailing using the fluted rod. J Bone Joint Surg [Am] 1985; 67-A:699-708

Harper MC, Henstorf J. Fractures of the femoral neck associated with technical errors in closed intramedullary nailing of the femur: report of two cases. J Bone Joint Surg [Am] 1986; 68-A:624-6.

Hooper GJ, Lyon DW. Closed unlocked nailing for comminuted femoral fractures. J Bone Joint Surg [Br] 1988; 70-B:619-21.

Johnson KD. Femoral shaft fractures. In: Browner BD, Jupiter JB, Levine AM, Trafton PG, eds. Skeletal trauma. Vol. 2. Philadelphia, etc: W. B. Saunders Co, 1992:1634.

Johnson KD, Tencer AF, Sherman MC. Biomechanical factors affecting fracture stability and femoral bursting in closed intramedullary nailing of femoral shaft fractures, with illustrative case presentations.J Orthop Truuma 1987; 1:1-11. 
King KF, Rush J. Closed intramedullary nailing of femoral shaft fractures: a review of one hundred and twelve cases treated by the Küntscher technique. J Bone Joint Surg [Am] 1981; 63-A:1319-23.

Küntscher G. Translated by Rinne HH. Practice of intramedullary nailing. Springfield, Illinois: Charles C Thomas, 1967.

McMaster WC, Prietto C, Rovner R. Closed treatment of femora fractures with the fluted Sampson intramedullary rod. Orthop Clin North Am 1980; 11:593-606.

Miller SD, Burkart B, Damson E, Shrive N, Bray RC. The effect of the entry hole for an intramedullary nail on the strength of the proximal femur. J Bone Joint Surg [Br] 1993; 75-B:202-6.

Noble PC, Alexander JW, Lindahl $\mathbf{L J}$, et al. The anatomic basis of femoral component design. Clin Orthop 1988; 235:148-65.

Rothwell AG. Closed Küntscher nailing for comminuted femoral shaft fractures. J Bone Joint Surg [Br] 1982; 64-B:12-6.
Swiontkowski MF. Ipsilateral femoral shaft and hip fractures. Orthop Clin North Am 1987; 18:73-84.

Swiontkowski MF, Hansen ST, Kellam JT. Ipsilateral fractures of the femoral neck and shaft: a treatment protocol. J Bone Joint Surg [Am] 1984; 66-A:260-8

Thompson F, O'Beirne J, Gallagher J, et al. Fractures of the femoral shaft treated by plating. Injury 1985; 16:535-8.

Winquist RA, Hansen ST Jr, Clawson DK. Closed intramedullary nailing of femoral fractures: a report of five hundred and twenty cases. $J$ Bone Joint Surg [Am] 1984; 66-A:529-39.

Wu CC, Shih CH. Ipsilateral femoral neck and shaft fractures. Acta Orthop Scand 1991; 62:346-51.

Zettas JP, Zettas P. Ipsilateral fractures of the femoral neck and shaft. Clin Orthop 1981; 160:63-73. 